\title{
Factors affecting academic self-efficacy and learning experiences of pharmacy students: Insights from a qualitative study in Zambia
}

\author{
Aubrey Chichonyi Kalungia ${ }^{1}$ iD, Micheal Chigunta ${ }^{2}$ iD , James Sichone² ${ }^{2}$ Bugewa Apampa ${ }^{3}$ (D) Sarah Marshall ${ }^{4}$, \\ Claire May ${ }^{5}$, Georgina Mulundu ${ }^{6}$, Chiluba Mwila ${ }^{1}$ (D), Sekelani Stanley Banda ${ }^{2}$ iD \\ 1 Department of Pharmacy, University of Zambia, Zambia \\ 2 Department of Medical Education Development, University of Zambia, Zambia \\ ${ }^{3}$ Birmingham City University, United Kingdom \\ ${ }^{4}$ Brighton \& Sussex Medical Schools, University of Sussex, United Kingdom \\ ${ }^{5}$ School of Pharmacy and Biomolecular Sciences, University of Brighton, United Kingdom \\ ${ }^{6}$ Department of Pathology \& Microbiology, University of Zambia, Zambia
}

\author{
Keywords \\ Factors \\ Learning experience \\ Pharmacy students \\ Self-efficacy \\ Zambia

\section{Correspondence} \\ Aubrey Chichonyi Kalungia \\ Department of Pharmacy \\ University of Zambia \\ PO Box 50110 \\ Lusaka \\ Zambia \\ ckalungia@unza.zm
}

\begin{abstract}
Background: Factors influencing how pharmacy students learn and experience pharmaceutical education have not been elucidated in Zambia. Aim: To elucidate contextual factors affecting academic self-efficacy and learning experiences among undergraduate pharmacy students at a public university in Zambia. Methods: A qualitative study utilising focus group discussions was conducted at the University of Zambia. Thirty-two undergraduate pharmacy students participated in four focus group discussions. Qualitative data were thematically analysed. Results: Four themes and eight sub-themes emerged from the data. Notional time management, learning style, and motivation; educational programme-related factors such as course load, the pace of teaching; the learning environment; and assessment practices affected undergraduate pharmacy students' self-efficacy and learning experiences. Conclusion: Addressing the student-related, educational programme-related, and the learning environment factors identified in this study will contribute to the improvement of undergraduate pharmacy students' learning experiences. This is premised to improve their educational outcomes and future practice of pharmaceutical care.
\end{abstract}

\section{Introduction}

How students learn has become important in defining their educational outcomes in contemporary pharmaceutical education (Biggs \& Tang, 2011). The way students learn can enhance or undermine their academic self-efficacy (Alt, 2015) and educational outcomes (Brown et al., 2015). Academic self-efficacy refers to an individual student's personal beliefs (convictions) and judgments of performance capabilities to successfully complete a particular level of academic task or domain of learning activity (Alt, 2015; Bandura, 1997). Often, a student's initial sense of self-efficacy for learning is shaped by various aptitudes, prior experiences and the educational environment (Bandura, 1997).

In Zambia, health professions' education standards and the quality of the graduates from the training institutions have, in the recent past, come under scrutiny for various reasons, with statutory regulators enhancing measures to assure the quality of health professions' graduates produced from various training programmes in the country (Health Professions Council of Zambia, 2019). At the University of Zambia (UNZA) the oldest and leading public university in Zambia, there was a recurring concern that attrition rates 
among cohorts of undergraduate pharmacy students remained relatively high (more than $10 \%$ ) over the years compared to other settings (Hassel et al., 2007). For instance, from 2011 to 2017, attrition rates among the Year 1 and 2 undergraduate pharmacy students on the Bachelor of Pharmacy (B. Pharm.) degree programme averaged $25 \%$ and $17 \%$, respectively, taking class sizes into account (unpublished data). This trend called for a diagnostic investigation, despite largely enrolling perceivably intelligent and high achieving students selected (as adjudged from their prior educational attainment scores) following a highly competitive admission process at all entry points of the Bachelor (B.Pharm.) programme. The B.Pharm. programme admits students using a points-based quota selection criterion into Year 1 after successful completion of foundational A-level subjects or those with relevant academic qualification admissible into the programme; and direct entry into Year 2 for applicants with a college diploma in pharmacy technology who meet other university admission requisites (Kalungia et al., 2019c).

Though attrition rates vary by institution and context, the students' perspectives about factors in their local educational environment that affect or impact their academic self-efficacy need to be known as these may increase their risk of attrition from a chosen study programme and future career prospects. Authors contend that the high attrition rates may have implications for both the learners and the training institution. For the learner, this can lead to increased education costs for sponsorship, loss of psychological self-esteem following exclusion from studies or slow progression towards completing their study programme. For the university, high failure rates reduce throughputs of much-needed health professionals graduating from the respective training programmes into the health workforce, negatively reflect on faculty's pedagogical effectiveness, and potentially affect the institution's attractiveness to potential students (Mlambo, 2011).

A number of studies (Azmi et al., 2014; Sansgiry, Bhosle, \& Sail, 2006; Sariem et al., 2014) conducted in different settings with varying general or context-specific findings identify possible causal factors that affect the learning and academic performance of pharmacy students, with interventions made to enhance learning skills (Kalungia et al., 2019a; Kridiotis \& Swart, 2017). The imperative need to conduct setting-specific diagnostic studies to identify and address factors associated with suboptimal academic performance among pharmacy students cannot be understated. Notwithstanding the need for low-middle income countries (LMICS) to address their human resource of health gaps through, among other things, increasing access and availability of educational opportunities for their nationals, a further need exists to address issues concerning the quality of educational processes and outcomes that higher learning institutions have to deal with (Kalungia et al., 2019c).

This study aimed to elucidate contextual factors affecting academic self-efficacy and learning experiences among undergraduate pharmacy students at a public university in Zambia. The findings of this study were premised to contribute towards the quality improvement of teaching and learning interventions for quality education outcomes in pharmaceutical education. Improving how undergraduate students learn and acquire knowledge, skills, and attitudes has far-reaching benefits for future practice as professionals when they graduate.

\section{Methods \\ Study design}

The design was a qualitative study utilising focus group discussions.

\section{Setting and context}

The study was conducted at UNZA in Zambia. The university has been providing higher education programmes in various professional disciplines since 1966. UNZA commenced offering pharmacy education programmes in 2001. The language of instruction at UNZA is English. This study was conducted in the School of Health Sciences, which offers a four-year, full-time B.Pharm. programme. The B.Pharm. programme has an annual enrolment capacity of about 350 undergraduate pharmacy students across the four years of study (Kalungia et al., 2019c), translating to an average class size of about 87 students in each cohort.

\section{Population and sampling}

Participants were the Year 1 and 2 undergraduate pharmacy students enrolled in the 2017 to 2018 academic year. According to official registers hosted at the Department of Pharmacy, 109 pharmacy students were enrolled in Year 1, and 66 were in Year 2 classes, respectively, during the academic year ending 2018. For this study, a convenience sampling method was used. Initially, an open invitation to participate, accompanied by a detailed information sheet about the study, was circulated to the cohorts. A total of 32 students (20 male, 12 female) responded to the open invitation and were recruited into the study after obtaining written informed consent. Participants were 
drawn only from the population of undergraduate pharmacy students at the university and did not include populations of students from other study programmes (Stalmeijer, McNaughton, \& Van Mook, 2014). In this study, preclinical (Year 1 and 2) undergraduate pharmacy students at UNZA were the population of interest. They were selected because there was preliminary evidence showing relatively high attrition rates recorded in cohorts over the recent years (Kalungia et al., 2019a). Compared to their clinical counterparts (Year 3 and 4 students) that were advanced in their pharmacy training and with lower attrition rates, students in Year 1 and 2 of undergraduate pharmacy education at UNZA were considered an information-rich population to provide valuable insights into factors that affect their academic self-efficacy and put them at risk of attrition from the B.Pharm. programme.

\section{Study period}

The duration of the study was from October 2017 to March 2018.

\section{Data collection procedure}

Focus group discussions (FGDs) were used to collect qualitative data. Participants were organised into four focus groups, each consisting of up to eight participants. The FGDs were conducted sequentially at suitable time slots outside participants' formal termtime scheduled academic activities. The duration of each FGD session was not more than 60 minutes. All FGDs were hosted in a relaxed environment that had a round-table free sitting arrangement. Each FGD session was audio-recorded verbatim. Two Bell pro-series digital voice recorders (DVR-5005I, Bell Office, Korea) placed at the opposite sides of the room were used to record the sessions. All FGDs sessions were conducted in English.

The FGDs were facilitated and moderated by ACK - the lead author. A research assistant helped schedule the FGDs, double-recorded the sessions, and took field notes and observations.

A semi-structured interview guide consisting of openended questions was used. The interview guide was pre-tested by the research team (ACK, MC, JS and SSB) prior to data collection. The same set of questions were used for each focus group, with few probing questions modified where necessary to solicit and accommodate further responses. Every effort was made to operationalise the principle of data saturation - a point of informational redundancy in a way that was consistent with the research question of this study (Saunders et al., 2018).

\section{Data analysis}

All audio recorded FGD sessions were double-checked for completeness and content transcribed verbatim onto transcripts in Microsoft Word. Data cleaning and reduction was made by extracting out irrelevant recordings and noise (that is, any information captured in the recording but not related to the communication of the message) before proceeding to the analysis. Open-ended responses to the discussion questions and probes were grouped and analysed using Clarke \& Braun's top-down, step-wise deductive (theoretical) thematic analysis procedure (Clarke \& Braun, 2013). Raw data were then organised to generate explanatory sort codes categorised into emerging sub-themes. Second-order coding enabled sub-themes to be grouped and categorised into main themes. The organisation, sorting and coding of qualitative data were done using Nvivo 11 software (QSR Int., Australia).

\section{Trustworthiness of data}

To assure the credibility of the study process, an appropriate data collection method suitable for the study design was utilised. FGDs, similar to one-on-one interviews, enjoy wide use to obtain contextually rich qualitative data (Stalmeijer et al., 2014). A meticulous approach to record-keeping of discussion sessions, decision trails, and transparent interpretation of data was used during data collection. Peer debriefing was done between the data collectors and the research team (co-authors), who reviewed the process and methods of data collection, including reviewing the transcripts and the data coding process that was used. An expert qualitative analyst based at UNZA was consulted to cross-check the data coding framework and consistency of derived themes from the analysis. This method of establishing and maintaining the consistency of qualitative data has been previously described (Pitney \& Parker, 2009). This also ensured analysis biases were eliminated; there were sufficient depth and relevance of data collection and analysis (Sandelowski, 1993), including controlling for and accounting for any other possible biases with the potential to influence findings reported (Morse et al., 2002).

To ensure dependability, respondent validation was done by inviting two selected participants from each focus group to preview the interview transcripts generated from the discussion sessions held with them and confirm they were a true reflection of the data 
collected. This was done by providing them with rich verbatim descriptions of participant's accounts and context to validate the data. The dependability of data was further enhanced by comparing and appraising the study findings with the existing literature (Kuper, Lingard \& Levinson, 2008).

\section{Ethical considerations}

Written informed consent was obtained from each participant. No names or personal details of participants were disclosed at any time. All qualitative data recordings and transcripts were encrypted and confidentially kept under lock and key. Despite the FGDs being facilitated by a faculty member involved in teaching undergraduate pharmacy students at the university, every effort was made to explain to participants the purpose of the study and the need for participants to express themselves freely without coercion or responder bias. All procedures performed were in accordance with the ethical standards of the institutional research committee (University of Zambia Biomedical Research Ethics Committee, IRB00001131 of IORG0000774). The approval reference is 008-06-17.

\section{Results}

\section{Presentation of findings}

Findings were outlined by themes and subthemes accordingly (Burnard et al., 2008). Selected anonymised verbatim quotes from participants' expressions were used to illustrate and confirm the findings. To ensure conformity with prescribed reporting formats for qualitative studies, every effort was made to conform to the Consolidated Criteria for Reporting Qualitative Research (COREQ) guidelines (Tong, Sainsbury \& Craig, 2007).

\section{Participants' attributes}

Attributes of the participants in the four focus groups are shown in Table I.

Table I: Demographic characteristics of participants

\begin{tabular}{lcc}
\hline Variable & $\begin{array}{c}\text { Frequ- } \\
\text { ency }\end{array}$ & $\begin{array}{c}\text { Percen- } \\
\text { tage }\end{array}$ \\
\hline Sex & & \\
Male & 20 & $62.5 \%$ \\
Female & 12 & $37.5 \%$ \\
\hline Year of study & & \\
Year 1 B.Pharm. & 16 & $50.0 \%$ \\
Year 2 B.Pharm. & 16 & $50.0 \%$ \\
\hline Prior learning & & \\
A-level Natural Sciences & 17 & $53.1 \%$ \\
Diploma in Pharmacy Technology & 15 & $46.9 \%$ \\
\hline
\end{tabular}

\section{Emerging themes}

Thematic analysis of qualitative data yielded four themes, eight subthemes and 22 categories (Figure 1).

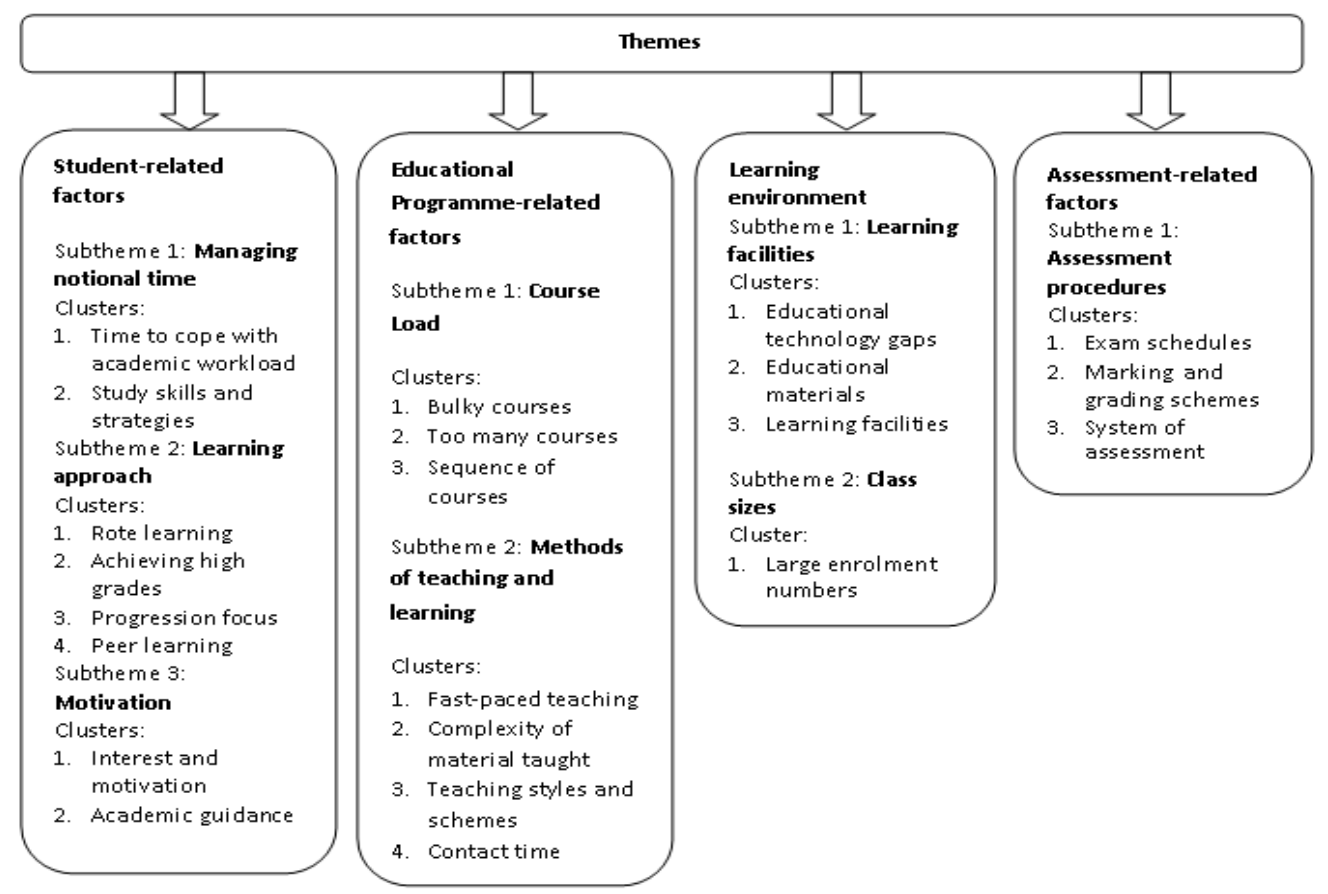

Figure 1. Emerging themes and subthemes from qualitative data 
The four themes were: student-related factors, educational programme-related factors, the learning environment, and assessment-related factors. The themes are elaborated in detail below. Since derived themes were not mutually exclusive, it was not surprising that some narratives were in certain instances a description of more than one theme or contents of another related subtheme or cluster category from within the data.

\section{Theme 1: Student-related factors}

\section{Subtheme 1: Managing notional time}

Participants expressed concerns regarding challenges with managing the notional time required to cope with the academic workload and tasks on the study programme.

"I think this can be very much attributed to the time and how much information that is being required of you to learn within a short time" - P1, FG1.

"I spend time trying to dig deeper in one course I'll find that I still do not have enough time for other courses" $-P 4, F G 3$.

Other participants felt time management was challenging because of having too many other competing needs for their time apart from academics. This concern was mostly expressed by participants that had prior or ongoing formal employment activities and other social commitments in addition to full-time study at the university.

"For me, I think it is mostly time, making time to handle things and balance time for everything" - P8, FG2.

"As a student, it's not only academic life that consumes time; there are other activities that are there" - P3, FG1.

Study skills and strategies emerged as another factor some participants felt they were not good at and contributed to how they ineffectively managed their learning time. P8 and P3 alluded to this.

"...the study skills from what I have observed. Not only from myself but also the study skills of how to study the topics and everything...." - P8, FG2.

"For me, it's about the study skill...., I find it hard to study because just after a certain point, I think I become saturated" - P3, FG3.

\section{Subtheme 2: Learning approaches}

Achieving high grades in assessments and progressing to the next academic stage of their training were apparent motives among the majority of the participants.
Characteristic features of a strategic learning approach were evident from the participants' expressions. Strategic learning refers to an approach characterised by the intention to maximise efficiency to achieve high grades, with alertness to assessment demands, organised studying, effort and time to only those materials appropriate to pass examinations (Lublin, 2003). The following were excerpts from participant's discussions that alluded to this.

"I have to strategise to make sure I pass. Here, you don't study to understand and know what you are studying but just formulate a manner that will let you gain the information into the test" - P3, FG1.

"As students, what we are interested in most of the time is progressing no matter what; it's about going forward" - P3, FG1.

"At times you just study not to understand but to memorise for an exam" - P7, FG1.

"For me, it is the grades that are important..." - P9, FG2.

Interestingly, other participants, such as P5, were able to express a different approach to learning that had features closely related to deep learning. Her point was in contrast to the other discussants.

I think for me, I am able to apply what I learn. For me, it does not sit well if I get $A+$ in a test, but after two weeks am unable to apply what I learnt" - P5, FG2.

To participants like P5, assessment grades attained did not seem to matter very much. P5 went on to further explain her approach to utilising peer learning as a strategy.

"There are challenges, but at least I was able to talk to my seniors, and they explained, and that helped me to understand medicinal chemistry later" - P5, FG2.

From P5's explanation, elements of peer learning emerged, which were also alluded to by other participants like P1, and to a great extent also advocated by P2.

"Yeah, you also get counselling from those who are ahead or in more years than us" - P1, FG2.

"[...] if we are going to work together at the end of the day I may know something which somebody might not know, and through working together we'll be able to share that" - P2, FG4.

\section{Subtheme 3: Motivation and guidance}

For newly enrolled undergraduate pharmacy students in the cohort, lack of motivation and academic 
guidance featured prominently in their discussion and seemed to affect their learning to a great extent.

"Looking at when we were received as new students if many people really took time to sit us down to say look what you are doing is this and this, and you'll be able to do well" - P4, FG3.

"Some friends, in the first week here, they said why don't you change programme [...], so those are some of the things that are confusing us" - P1, FG4.

\section{Theme 2: Educational programme-related factors}

\section{Subtheme 1: Course load}

The majority of participants expressed concerns related to high course load and voluminous content coverage of the academic subjects they were taking on the B.Pharm. Programme.

"For me, the lectures are too bulky" - P7, FG1.

"There is so much to do. In this place, they are so bulky; nothing is left out. And in that bulkiness, you are expected to know every little part of it" - P8, FG1.

"[...] because of the bulkiness of what you supposed to do and also what you are required to know, we tend to panic [...]." - P10, FG1.

Other participants also felt the high course load was further compounded by the large class sizes, which make the educational environment challenging to cope with.

"Too many courses [...], we have a lot of courses, and there are a lot of us" - P5, FG1.

Some participants felt the high course load was further complicated by having a number of combined courses addressing different subject areas, the complex nature of course content, and how lecturers taught the courses. This was what they expressed:

"You will find that in one course, like Comparative Anatomy and Physiology, Computer Sciences and Social Sciences, Molecular Cell Biology and Microbiology [...] they are two in one and each of these components has their own lecturer to teach [...] I would prefer if they were separate courses like they were at first" - P3, FG4.

"So now the main disadvantage here is that the courses are many, it is bulky" - P1, FG4.

\section{Subtheme 2: Pace of teaching and learning}

When asked about ways teaching and learning was facilitated by lecturers, it emerged that the pedagogical skills and teaching styles were also a cause of concern among participants. Particular concern was expressed over lecturers' organisation, time management, commitment to teaching duty, and helping students learn.

"Most of the time lecturers don't have time; they just rush through everything, we don't even understand. There was not even time for us to ask questions" - P1, FG4.

Another participant from the Year 1 cohort expressed concern about some lecturers' commitment to teaching schedules, saying:

"By this time, 4 to 5 months have gone by since we started learning, but other lecturers have not even met us, we don't know if they are still preparing or not coming, we don't know" - P6, FG4.

Other participants expressed concerns about the fastpaced teaching delivery during the academic year. The participants seemed to allude to the observation that lecturers tended to congest content delivery towards the end of the academic year as examinations drew close.

"When we open next term, lecturers will probably be cruising for them to catch up, and it will be too late for us" $-P 2$, FG4.

"[...] and the way I know these people (lecturers), honestly speaking, when it comes to cruising through lectures they don't spare, it will now be up to you to cope with them"-P1, FG4.

"Looking at the pace at which we are doing the school work, I think it is too fast for me to keep up with the pace of some courses" - P1, FG3.

"That is exactly how I feel, you'll find that you're having challenges with catching up with the lecturer who is at a different pace than you" - P6, FG2.

\section{Theme 3: Learning environment}

\section{Subtheme 1: Learning facilities}

When asked about the putative influence of the educational environment, participants expressed their concerns about the learning facilities.

"As pharmacy students, we are people who are supposed to acquire knowledge of how to synthesise drugs, but if we try to look around, such opportunities are not there" - P3, FG4. 
These perceptions by P3 perhaps pointed to existing inadequacies of educational facilities used for experiential, practicum and simulated learning of the pharmaceutical sciences. P3 further went on to say:

"We are being trained to go out there to be in the pharmaceutical industry so that we produce out there, [...] but we are not seeing such kind of stuff in the training. So, in short, what I can say is lacking is adequate facilities that will enhance our learning skills" - P3, FG4.

Other participants like P1, P9 and P7 felt the inadequate study materials and educational resources to support their learning on the programme affected their academic performance.

"I think what can affect my academic performance is the lack of adequate study materials. So due to inadequate access to some study materials, the study skills get affected" - P1, FG3.

"Sometimes books; some books are not available" P9, FG2.

"Sometimes there is no internet..." - P7, FG2.

\section{Subtheme 2: Class size}

Participants expressed concerns about large class sizes and student enrolment numbers being a factor adversely affecting the quality of learning. P7 expressed this in no uncertain terms.

"We are too many, how we'll be taught will be different from those who are few because of the number [...] with the 107 of us (in class) they (lecturers) cannot manage us all." - P7, FG2.

\section{Theme 4: Assessment-related factors}

\section{Subtheme 1: Examination processes}

Among all the four focus groups, participants expressed their discomfort and difficulties experienced with summative assessment modalities on the study programme. Concerns ranged from the way examinations were scheduled to how they are conducted and graded.

"You'll find the examination timetable does not have breathing space. You are writing (examinations) today, tomorrow you are writing, the other day you're writing" - P3, FG1.

"They should come up with a way where they consult students when making the exam timetable" - P5, FG1.
"Sometimes I feel like the exam timetable can determine whether someone will do well or not" P4, FG1.

Another participant felt the way summative assessments were scheduled could be driving low confidence and fear of failure among the pharmacy students at the university.

"There are even instances you know the information but not having enough time to revise for you to gain the confidence to go and face the exams" - P3, FG1.

Some students tended to become so familiar with the system of assessment that they narrowed their focus to study only those taught materials they felt were sufficient content to memorise for purposes of passing the examinations.

"There are just certain materials that you need to pass, so if you go beyond that to read other things, you won't get there" - P3, FG2.

"There are some (lecturers) like over a decade they've just been using the same materials for assessment, so if you do not familiarise yourself with those materials then you fail" - P1, FG2.

From the various perspectives expressed by participants concerning their learning experiences, including factors affecting their academic self-efficacy, there was a case for educators and education policymakers to consider these as feedback for correctional action and quality improvement.

\section{Discussion}

This study qualitatively elucidated the key contextual factors affecting and impacting the academic selfefficacy and learning experiences of undergraduate pharmacy students in Zambia. This is the first qualitative methodological study to investigate and explain the factors affecting the way undergraduate students learn on a pharmacy programme in Zambia.

Study findings suggest that early-year undergraduate pharmacy students found notional time demands on the B.Pharm. programme challenging to manage. Notional time refers to the learning hours taken by an 'average' student to achieve the specified learning outcomes of the course, unit or programme of study. Notional time includes teaching contact time (lectures, seminars, tutorials, laboratory practicum, workshops, fieldwork, etc.), time spent studying, preparing and carrying out assignments and examinations, whether in 
term-time or during vacations (University of South Africa, 2017). Although not a precise measure, notional hours provide students and educators with an indication of the amount of study and level of commitment expected to achieve the learning outcomes. This factor was more pronounced among those much older students who combined formal employment activities and other social responsibilities with full-time study at the university. Older students are, therefore, more often at increased risk of nonprogression, arguably due to additional financial pressures to afford a university education, family responsibilities, and perhaps a greater time lapse between their prior learning and the onset of the B.Pharm. programme. Existing evidence has shown that work-school conflict has a significant positive relationship with perceived academic workload (Adebayo, 2006). Time management has been described as clusters of behavioural skill sets that are important in the organisation of study or course load (Sansgiry et al., 2006). Time management skills include activities performed by students such as planning in advance, prioritising work, test preparation, and following scheduled academic activities.

Pharmacy students' self-efficacy towards learning tasks was found to be affected by lack of adequate study skills. The feeling of inadequacy expressed by participants in this study may be a generally crosscutting feature among a number of pharmacy students at the university. This finding also agreed with previous evidence by Ezeala and Siyanga, who demonstrated that undergraduate pharmacy students at UNZA lacked adequate study skills (Ezeala \& Siyanga, 2015). Educational interventions tried locally to address this gap, including those that advocate a deep learning approach among pharmacy students at UNZA, showed a minimal positive effect on influencing students' approach to studying (Kalungia et al., 2019b). Similarly, in this study, qualitative findings showed that participants were more driven by a focus on achieving high grades in tests and examinations (strategic learning approach) as their benchmark for academic success, and not necessarily understanding for application (deep learning approach) of what they learnt on the B.Pharm. programme. This finding confirmed previous evidence by Kalungia and colleagues (Kalungia et al., 2019b). Arguably, the dominance of a strategic approach to learning associated with rote learning outcomes was considered by most participants as a coping mechanism required to 'survive and progress' on the B.Pharm. programme and university education in general. As earlier described by Haylock, rote learning refers to an outcome of learning in which the student seeks only to retain and later to recall some information, result or process, without necessarily making cognitive connections between the new learning and their existing network of understanding (Haylock, 2007). Whereas the benefits of this approach may seem useful to the student in the short term, there may be long term disadvantages as it has the potential to affect the students' application of concepts in their future practice as health professionals.

From the participants' expressions, it became apparent that peer learning, as a strategy, was entirely an individual student's initiative and not an aspect deliberately incorporated into the curriculum's educational strategies. Boud described peer learning as students' ability to learn with and from each other as fellow learners without any implied authority to any individual (Boud, 2001). Scholars have suggested that well-designed peer learning is optimised when incorporated as an integral component of a curriculum, paying special attention to creating conducive educational environments where students build mutual respect for and trust and confidence in one another, with the freedom to express opinions, test ideas, and ask for, or offer help when it is needed (Gwee, 2003). That way, students who engage in collaborative learning and group study tend to perform better academically, persist longer, feel better about the educational experience, and enhance self-esteem. Such learners are individually and collectively accountable for optimising their own learning and achievement of the expected outcomes of the learning (Landis, 2013). An opportunity exists for peer learning to be employed as a strategy for students to learn from each other. Using this strategy, students learn a great deal by explaining their ideas to others and participating in activities in which they can learn from their peers. It was not uncommon at the university to find students using peer learning in small study groups they constituted based on shared learning needs and objectives.

High course load and voluminous content coverage on the B. Pharm. programme offered in Zambia negatively influenced the ability to learn effectively among undergraduate pharmacy students. This finding corroborated evidence from Sansgiry and colleagues that high course load was a factor affecting academic performance among pharmacy students (Sansgiry \& Sail, 2006). At UNZA, the current B.Pharm. curriculum requires that Year 1 students undertake five common core full-courses each having credit point level at 5.0 and one half-course with 2.5 credit point level. In Year 2 , students are expected to complete six full courses in pharmaceutical sciences (each with 5.0 credit points). The university-wide recommended course load for 
undergraduate students taking health science programmes is not more than four to five full courses in an academic year. Each course has no more than 150 credit hours of structured learning (Kalungia et al., 2019c).

Whereas students' perception of course load has been shown to be associated with test anxiety, fear of failure, and inability to effectively manage time for course work (Sansgiry \& Sail, 2006), a growing body of evidence shows that vertical integration of problem-based learning (PBL) methods, which include simulated and clinical learning exposures in medical and healthcare fields, help students to understand better the context of what they are learning, reduce content volume, and increase their motivation (McLean, 2016).

The influence of motivation and academic guidance on students' self-efficacy cannot be understated. Findings of this study showed that participants felt a lack of motivation and academic guidance was affecting their academic self-efficacy. Literature shows that motivation has a positive influence on study strategy, academic performance, adjustment and well-being among students, and positive motivation correlates with academic performance (Kusurkar et al., 2013). Moreover, this study findings showed that undergraduate pharmacy students perceived the lecturers' teaching styles as fast-paced and challenging to cope with. This agreed with previous findings (UNZA, Department of Medical Education Development, 2016). Arguably, the concerns expressed by participants may further point to an indirect effect the curriculum structure, educational strategies, the academic course workload, and notional time allocated may have on learning when not planned or implemented properly. Findings showed that, among other factors, there was an inherent mismatch between the teaching process and the learning appreciation by the students. From participants' views, not having purpose-built learning facilities for delivering pharmaceutical education at the university was asserted as a cause for concern. These were genuine concerns given that participants felt that such facilities were lacking in the current educational environment. Adequate and suitable learning facilities effectively enhance students' self-efficacy towards becoming well-trained pharmacists. There is, therefore, a need to leverage a sufficient mix of educational exposures and infrastructure to support the practical aspects of training pharmacists in Zambia.

Literature suggests large class sizes affect student's quality of learning. According to Heinesen's argument, class size is one of the key factors with a general negative relationship and impact on learning and academic performance (Heinesen, 2010). Studies have shown that class size negatively influences assessment modalities on the course (Persky \& Pollack, 2010), student accountability and motivation (Hassel \& Lourey, 2005), academic performance (Jepsen \& Rivkin, 2009) and types of learning outcomes that can be achieved (Lopez, 2004). Johnson suggested that further trimming enrolment in small classes than reducing class size overall could attain a larger impact on student performance (Johnson, 2010). The International Pharmaceutical Federation (FIP) Education Committee's minimum quantitative standards for undergraduate pharmacy degree programmes indicate that the overall ratio between lecturer and student for a pharmacy programme is recommended to be at least $1: 10$, and for the clinical years, it should be $1: 8$ (International Pharmaceutical Federation, 2010). For public universities in Zambia, the paradox of economics of scale driving high enrolment numbers and class sizes versus pedagogically desirable and manageable class sizes has resulted in some complex and sometimes contentious programme design and delivery issues. The impact of this on the educational environment will be worth investigating.

Perceptions expressed by participants in this study showed that the nature of assessment practice adopted by educators affected students' self-efficacy and academic outcomes to a great extent. There exists a very close cross-talk between the quality of assessment practice and the quality of student learning. The fidelity, reliability and defensibility of summative assessments in pharmaceutical education programmes may need improvement in most settings. This can be in terms of assessment timing, design, and formats by considering methods that bring together all the requisite, appropriately pitched cognitive knowledge, skill abilities, and experience into performance expected in the real practice of healthcare (Kalungia et al., 2019b).

\section{Implications for pharmaceutical education policy and practice}

Pharmaceutical education, its processes and strategies, including assessment methods, should strive to promote the attainment of quality learning outcomes by the learners (Ofstad \& Brunner, 2013). To a great extent, the findings of this study explain some of the reasons there exists a predominantly strategic approach to learning among the majority of undergraduate pharmacy students in Zambia as reported by Kalungia and colleagues (Kalungia et al., 2019b). This may reflect issues associated with the high course workload in the curriculum. Authors contend that curriculum developers can consider, in future, 
mainstreaming the concept of a common core curriculum that focuses on the vital few (essential) high impact competence areas while minimising the trivial many 'nice to know' subject areas that make up the current pharmacy curriculum. The future curriculum should consider the possibility of providing optional (elective) courses or modules that enable students to go into more depth in an area of particular interest and prepares them for careers in pharmacy. Moreover, teaching strategies and assessment methods employed in pharmaceutical education should be deliberately designed to ensure the cognitive development of undergraduate students in the context of Bloom's taxonomy of higher-order critical thinking skills (Kim et al., 2012).

The findings of this study have the potential to impact the pharmaceutical education sector's adoption of much more constructivist approaches to training pharmacists not only in Zambia but other LMIC settings with similar training models, including the design of educational strategies which potentially go on to improve the quality of learning experiences among current and future pharmacy students. Ultimately, the desired improvement may positively impact future pharmaceutical care practice by training competent pharmacists who have high self-efficacy, are critical thinkers, problem-solvers, leaders, and innovators of quality health care products and services.

\section{Limitations of the study}

Although the monocentric nature of this study at one public university and one population of interest (undergraduate pharmacy students in Zambia) may have limited transferability of its findings, ecological validity to the real-world setting was still demonstrated by the findings contributing to and corroborating the existing literature. Future studies can explore and compare factors affecting other student populations in health professions education, the faculty, and other stakeholders involved in pharmacy education programmes across countries.

\section{Conclusion}

Student-related, educational programme-related, the learning environment, and assessment-related factors negatively affect the academic self-efficacy and learning experiences of undergraduate pharmacy students in Zambia. Among the student-related factors, managing notional time was a substantial challenge most pharmacy students encountered when attempting to cope with the academic workload. In the learning environment, inadequate educational facilities and large class sizes affected the quality of learning. The philosophy of assessments was also highlighted as an aspect that educators need to address to drive student learning in the appropriate direction and effectively measure meaningful learning outcomes.

\section{Conflict of interest disclosure}

All authors declare no conflict of interest associated with this work.

\section{Funding disclosure}

None.

\section{References}

Adebayo, D. O. (2006). Workload, Social Support, and WorkSchool Conflict Among Nigerian Nontraditional Students. Journal of Career Development, 33(2), 125-141. https://doi.org/10.1177/0894845306289674

Alt, D. (2015). Assessing the contribution of a constructivist learning environment to academic self-efficacy in higher education. Learning Environments Research, 18(1), 47-67. https://doi.org/10.1007/s10984-015-9174-5

Azmi, N., Ali, A. M., Wong, X. L., \& Kumolosasi, E. J. (2014). Internal factors affecting academic performance among pharmacy students in Malaysian public institutions of higher learning. Indian Journal of Pharmaceutical Education and Research, 48(3), 26-33. https://doi.org/10.5530/ijper.48.3.5

Bandura, A. (1997). Self-efficacy: The exercise of control. New York

Biggs, J. B., \& Tang, C. (2011). Teaching for quality learning at university: What the student does (4th ed.). Berkshire, UK: McGraw-Hill Education

Boud, D. (2001). Introduction: Making the Move to Peer Learning. In D. Boud, R. Cohen, \& J. Sampson (Eds.), Peer Learning in Higher Education: Learning From \& With Each Other (pp. 1 - 17). London: Kogan Page Ltd

Brown, S., White, S., Wakeling, L., \& Naiker, M. (2015). Approaches and Study Skills Inventory for Students (ASSIST) in an introductory course in chemistry. Journal of University Teaching \& Learning Practice, 12(3), 1-12. Available at: http://ro.uow.edu.au/jutlp/vol12/iss3/6/

Burnard, P., Gill, P., Stewart, K., Treasure, E., \& Chadwick, B. (2008). Analysing and presenting qualitative data. Bdj, 204, 429. https://doi.org/10.1038/sj.bdj.2008.292

Clarke, V., \& Braun, V. (2013). Teaching thematic analysis: Overcoming challenges and developing strategies for effective learning. The psychologist, 26(2), 120-123. Available at: 
http://www.thepsychologist.org.uk/archive/archive_home.c $\mathrm{fm}$ ?volumelD=26\&editionID=222\&ArticleID=2222

Ezeala, C. C., \& Siyanga, N. (2015). Analysis of the study skills of undergraduate pharmacy students of the University of Zambia, School of Medicine. Journal of Educational Evaluation for Health Professions, 12(46). https://doi.org/10.3352/jeehp.2015.12

Gwee, M. C. (2003). Peer Learning: Enhancing Student Learning Outcomes. Available at: http://www.cdtl.nus.edu.sg/success/sl13.htm

Hassel, H., \& Lourey, J. (2005). The dea(r)th of student responsibility. College Teaching, 53(1), 2-13. https://doi.org/10.3200/CTCH.53.1.2-13

Hassel, K., Sestan, E., Eden, M., \& Willis, S. (2007). The UK pharmacy degree: Attrition rates and demographics of noncompleters. Pharmacy Education, 7(3), 249 - 256. Available at: http://pharmacyeducation.fip.org/pharmacyeducation/article/ download/148/124

Haylock, D. (2007). Key Concepts in Teaching Primary Mathematics. In. London: SAGE Publications Ltd

Health Professions Council of Zambia. (2019). Licensure examinations phased out, replaced with alternative monitoring mechanisms [Press release]. Available at: http://www.moh.gov.zm/?p=6113

Heinesen, E. (2010). Estimating Class-size Effects using Within-school Variation in Subject-specific Classes. The Economic Journal, 120(545), 737-760. https://doi.org/10.1111/j.1468-0297.2009.02301.x

International Pharmaceutical Federation. (2010). FIP Guidelines on Recognition of A Pharmacy Training Programme: Minimum Quantitative Standard For Undergraduate Pharmacy Degree Programme (FIPEd Committee). FIP, UNESCO UniTwin Network

Jepsen, C., \& Rivkin, S. (2009). Class size reduction and student achievement the potential tradeoff between teacher quality and class size. Journal of human resources, 44(1), 223250. https://doi.org/10.3368/jhr.44.1.223

Johnson, I. Y. (2010). Class Size and Student Performance at a Public Research University: A Cross-Classified Model. Research in Higher Education, 51(8), 701-723. https://doi.org/10.1007/s11162-010-9179-y

Kalungia, A. C., Kaonga, P., Munkombwe, D., Mulundu, G., Chigunta, M., Sichone, J., \& Banda, S. S. (2019). Development and Evaluation of an Educational Intervention to Enhance Deep Learning and Study Skills among Pharmacy Students in Zambia. Education, 9(4), 68-75. https://doi.org/10.5923/j.edu.20190904.02

Kalungia, A. C., Munkombwe, D., Kaonga, P., Nzala, S., Apampa, B., Mulundu, G., \& Banda, S. S. (2019). Learning approach and teaching style preferred by pharmacy students: Implications for educational strategies in Zambia. Pharmacy Education, 19(1), 116-125. Available at: http://pharmacyeducation.fip.org/pharmacyeducation/artic le/view/739/725

Kalungia, A. C., Muungo, L. T., Marshall, S., Apampa, B., May, C., \& Munkombwe, D. (2019). Training of pharmacists in Zambia: Developments, curriculum structure and future perspectives. Pharmacy Education, 19(1), 69-78. Available at: http://54.77.129.155/pharmacyeducation/article/view/638

Kim, M.-K., Patel, R. A., Uchizono, J. A., \& Beck, L. (2012). Incorporation of Bloom's taxonomy into multiple-choice examination questions for a pharmacotherapeutics course. American Journal of Pharmaceutical Education, 76(6), 114. https://doi.org/10.5688/ajpe766114

Kridiotis, C.-A., \& Swart, S. (2017). A learning development module to support academically unsuccessful 1st-year medical students. African Journal of Health Professions Education, 9(2), 62-66. https://doi.org/10.7196/AJHPE.2017.v9i2.694

Kuper, A., Lingard, L., \& Levinson, W. (2008). Critically appraising qualitative research. BMJ, 337, a1035 https://doi.org/10.1136/bmj.a1035

Kusurkar, R. A., Ten Cate, T. J., Vos, C. M. P., Westers, P., \& Croiset, G. (2013). How motivation affects academic performance: a structural equation modelling analysis. Advances in Health Sciences Education, 18(1), 57-69. https://doi.org/10.1007/s10459-012-9354-3

Landis, R. B. (2013). Academic Success Strategies. In R. B. Landis (Ed.), Studying Engineering: A Road Map to a Rewarding Career (4th ed.). Los Angeles: Discovery Press

Lopez, E. (2004). McKeachie's teaching tips: Strategies, research, and theory for college and university teachers. The Review of Higher Education, 27(2), 283-284. https://doi.org/10.1353/rhe.2003.0066

McLean, S. F. (2016). Case-Based Learning and its Application in Medical and Health-Care Fields: A Review of Worldwide Literature. Journal of Medical Education and Curricular Development, 3 JMECD.S20377. https://doi.org/10.4137/jmecd.S20377

Mlambo, V. (2011). An analysis of some factors affecting student academic performance in an introductory biochemistry course at the University of the West Indies. The Caribbean Teaching Scholar, 1(2), 79 - 92. Available at: https://journals.sta.uwi.edu/ojs/index.php/cts/article/view/ $10 / 7$

Morse, J. M., Barrett, M., Mayan, M., Olson, K., \& Spiers, J. (2002). Verification Strategies for Establishing Reliability and Validity in Qualitative Research. International Journal of Qualitative Methods, 1(2), 13-22. https://doi.org/10.1177/160940690200100202

Ofstad, W., \& Brunner, L. J. (2013). Team-based learning in pharmacy education. American Journal of Pharmaceutical Education, 77(4), 70. https://doi.org/10.5688/ajpe77470

Persky, A. M., \& Pollack, G. M. (2010). Transforming a LargeClass Lecture Course to a Smaller-Group Interactive Course. American Journal of Pharmaceutical Education, 74(9), 170. https://doi.org/10.5688/aj7409170

Pitney, W. A., \& Parker, J. (2009). Qualitative research in physical activity and the health professions: Human Kinetics Champaign, IL.

Sandelowski, M. (1993). Rigor or rigor mortis: the problem of rigor in qualitative research revisited. ANS. Advances in nursing science, 16(2), 1-8. https://doi.org/10.1097/00012272-199312000-00002

Sansgiry, S. S., Bhosle, M., \& Sail, K. (2006). Factors that affect academic performance among pharmacy students. American Journal of Pharmaceutical Education, 70(5), 104 https://doi.org/10.5688/aj7005104

Sansgiry, S. S., \& Sail, K. (2006). Effect of Students' Perceptions of Course Load on Test Anxiety. American Journal of Pharmaceutical Education, 70(2), 26. https://doi.org/10.5688/aj700226 
Sariem, C. N., Fwangshak, F. D., Shalkur, D., \& Adeniyi, M. A. (2014). Factors affecting academic performance of Pharmacy students in the University of Jos, Nigeria. Journal of Pharmacy \& Bioresources, 11(2), 85-92. Available at: http://cactus.unijos.edu.ng/jspui/handle/123456789/1332

Saunders, B., Sim, J., Kingstone, T., Baker, S., Waterfield, J., Bartlam, B., Burroughs, H., \& Jinks, C. (2018). Saturation in qualitative research: exploring its conceptualization and operationalization. Quality \& Quantity, 52(4), 1893-1907. https://doi.org/10.1007/s11135-017-0574-8

Stalmeijer, R. E., McNaughton, N., \& Van Mook, W. N. K. A. (2014). Using focus groups in medical education research: AMEE Guide No. 91. Medical Teacher, 36(11), 923-939. https://doi.org/10.3109/0142159x.2014.917165

Tong, A., Sainsbury, P., \& Craig, J. (2007). Consolidated criteria for reporting qualitative research (COREQ): a 32-item checklist for interviews and focus groups. International Journal for Quality in Health Care, 19(6), 349-357. https://doi.org/10.1093/intqhc/mzm042

University of South Africa. (2017). Qualifications: credits, modules and NQF levels. Available at: https://www.unisa.ac.za/sites/corporate/default/Apply-foradmission/Student-fees-and-funding-your-

studies/Qualifications:-credits,-modules-and-NQF-levels

University of Zambia - Department of Medical Education Development. (2016). A preliminary report of teaching and learning at the School of Medicine, University of Zambia 2015-2016 (01) 